\title{
Purification of Tannery Effluent by Electrolytic Corrosion of Aluminum
}

Grant A. Mathieson, Alan Langdon and Graham Jamieson

ECS Trans. 2006, Volume 1, Issue 4, Pages 93-102. doi: $10.1149 / 1.2215493$
Email alerting
Receive free email alerts when new articles cite this article - sign up in the service box at the top right corner of the article or click here

To subscribe to ECS Transactions go to: http://ecst.ecsdl.org/subscriptions

(C) 2006 ECS - The Electrochemical Society 


\title{
Purification of Tannery Effluent by Electrolytic Corrosion of Aluminum
}

\author{
Grant Mathieson $^{1}$, Alan Langdon ${ }^{1}$, Graham Jamieson ${ }^{2}$ \\ 1. University of Waikato, Departments of Chemistry and \\ Materials and Process Engineering. \\ 2 Works Filter Systems Limited \\ Address for correspondence: Chemistry Department, \\ University of Waikato, Private Bag 3105, Hamilton, New Zealand. \\ e-mail: gam10@waikato.ac.nz
}

\begin{abstract}
Electrolytic processing of noxious Tannery Effluent is feasible because the high salt content of the effluent gives a high electrical conductivity. While research on the subject dates back to 1914, commercialization has not yet occurred, perhaps due to excessive power consumption. The goal of treatment is removal of both suspended solid and dissolved chromium. A specialised proprietary prototype with a aluminum anode design was trialed extensively and produced good results with low power consumption during continuous inline operation despite wide variation in the composition of the inflow. Greater than $90 \%$ removal of chromium from solution with similar reductions in turbidity were achieved. In particular, the excellent performance with low residual aluminum for inflow $\mathrm{pH}$ in excess of 9.5 was unexpected. Laboratory experiments using synthetic effluent were carried out in order to discern the advantages of the electrolytic system in particular circumstances, including the use of pulsed power.
\end{abstract}

\section{INTRODUCTION}

Tannery Effluent is particularly noxious, because the chemicals used in the tanning process are preservatives, including chromium compounds, and the $\mathrm{pH}$ tends to be high. Electrolytic processing is feasible because the high salt content of the effluent gives a high electrical conductivity. While research on the subject dates back to early in the 20th Century, $(1,2)$ commercialization has not occurred, perhaps due to excessive power consumption. Other researchers have produced promising results with rendering plant effluent (3). In 2004 Works Filter Systems Limited was invited to trial an electrolytic effluent processor at a Tannery site in the Eastern Waikato farming region of New Zealand. The high suspended solids content of the effluent to be treated set the emphasis on electro-flotation by bubbles produced at a cathode and electro-flocculation by aluminum corroded from the anode. Although the final goal was to reduce both the Coliform count and suspended or dissolved material in the terminal effluent the direct electro-sterilization of the tannery effluent was considered to be both counter-productive to downstream oxidation pond function and prohibitively energy consuming. The goal of treatment was removal of both suspended solid and dissolved chromium. Hence, the processing systems were designed to corrode an aluminum anode with high current efficiency and produce fine bubbles. A specialised proprietary prototype effluent processor with a novel anode design was trialed extensively and produced good results during continuous inline operation despite wide variation in the composition of the inflow. 
Greater than $90 \%$ removal of chromium from solution with similar reductions in turbidity were achieved at lower operating cost, residual aluminum and total aluminum addition than by dosing with usual commercial aluminum based flocculants such as polyaluminum chloride. Results from the field trials are shown and discussed. While the treatment system performed well in the challenging conditions of a real tannery, the mechanism of operation was difficult to discern in the field. This was because of the numerous compounds in the effluent and the rapidly varying absolute and relative levels of the component impurities. In particular, the excellent performance with low residual aluminum at $\mathrm{pH}$ in excess of 9.5 was unexpected given the high solubility of aluminum at that $\mathrm{pH}$. Laboratory experiments using synthetic effluent based on the inorganic chemicals used in the real process were carried out in order to discern the advantages of the electrolytic system in particular circumstances, and to characterize the electrolytic corrosion and resultant purification in response to numerous combinations of salinity, $\mathrm{pH}$ and alkalinity. Results from these experiments are presented, along with analysis and interpretation. The effect of pulsed voltage waveforms was also trialed at the tannery, but any effects were swamped by the rapid variations in the effluent content. Again, by using synthetic effluent in laboratory conditions, the effects could be studied.

\section{ELECTROLYTIC TREATMENT OF DILUTE SOLUTIONS}

The simple challenge in electrolytic treatment of dilute solutions is the low conductivity of the water. This is represented by the term $R_{E}$ in Figure 1 .

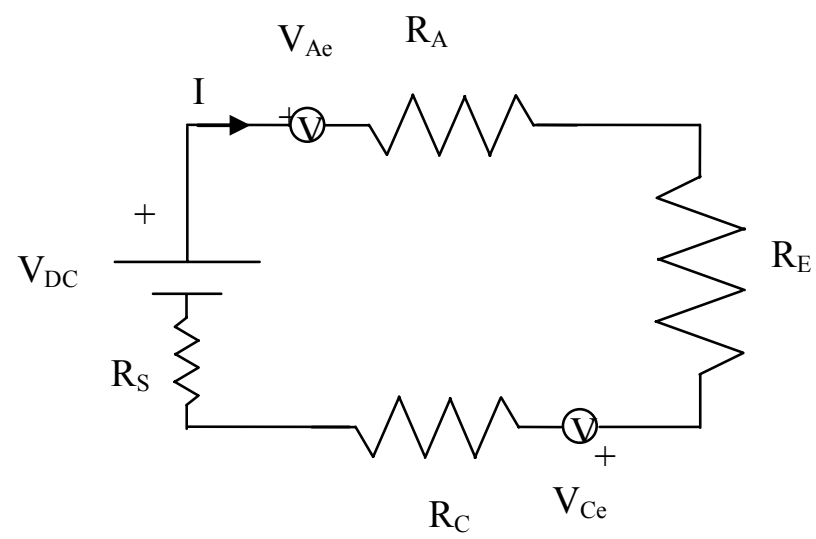

Figure 1. The DC electrical equivalent of an electrolytic cell.

The equilibrium potentials for the anode and cathode are $\mathrm{V}_{\mathrm{Ae}}$ and $\mathrm{V}_{\mathrm{Ce}}$ respectively. These cannot necessarily be considered constant with respect to current because both the $\mathrm{pH}$ and temperature are subject to alteration by the passage of current. The resistance of the supply, $\mathrm{R}_{\mathrm{S}}$, including metallic leads and the electrolyte are considered to be ohmic (linear) functions of the current. This is well justified for $R_{S}$, but as shall be explained later, the electrolyte resistance is likely to depart from ohmic behaviour at high current densities. The anodic and cathodic overvoltages are $\eta_{\mathrm{A}}$ and $\eta_{\mathrm{C}}$.

Figure 2 shows how the voltage drop across the electrolyte gap becomes dominant if the electrolyte conductivity is reduced, and how reducing the gap size can lower the losses. This result is based on iron cathode exchange current data (4). 


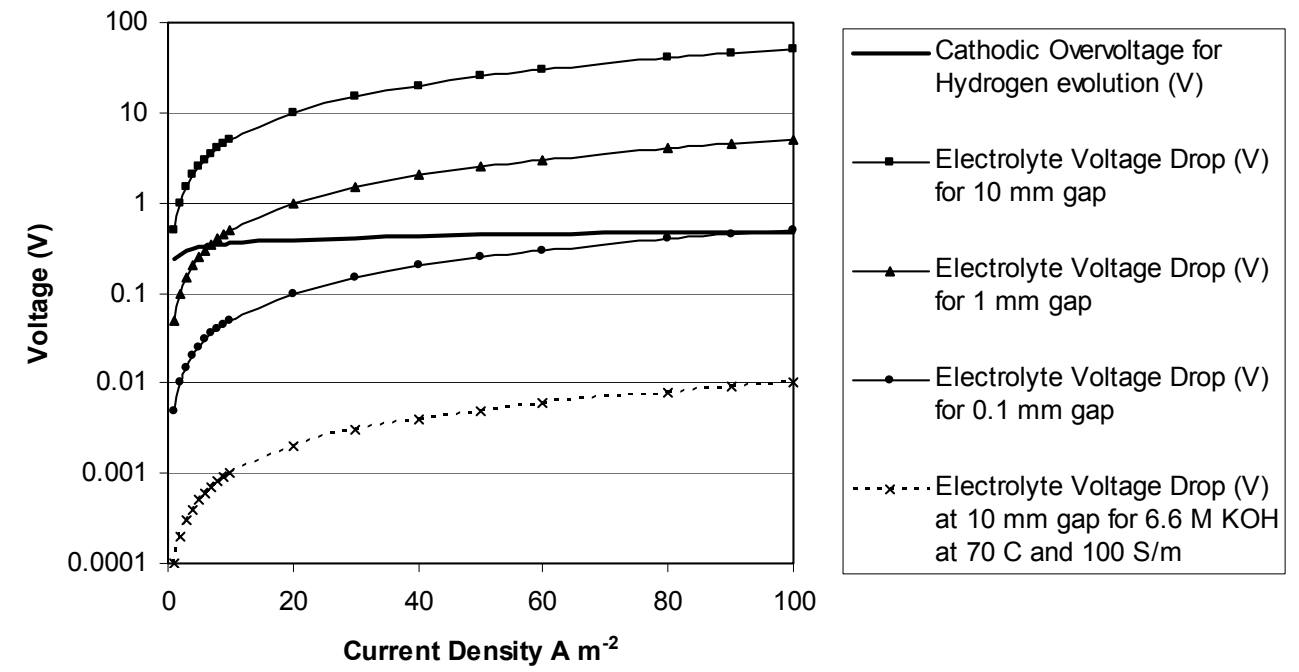

Figure 2. How electrolyte voltage drop is lowered to the order of the cathodic overvoltage by reducing the gap. Based on an iron cathode and fluid with $0.02 \mathrm{~S} \mathrm{~m}^{-1}$ conductivity like tap water. Result for concentrated electrolyte shown for comparison.

Partial occlusion of the electrolyte gap by gas bubbles leads to an increase in effective electrolyte resistance. Two extreme forms are explored for illustration:

i) If a contiguous sheet of gas forms between two electrodes from bubbles that coalesce, this will grossly increase the effective resistance of the electrolyte even if it does not fill the entire space, hence this is to be avoided if at all possible.

ii) Evenly dispersed fine bubbles will reduce the electrolyte conductivity from $\kappa_{0}$ to $\kappa$ slightly more than predicted by the linear gas void to total volume ratio, $\varepsilon_{\mathrm{g}}$,

iii) Theoretical estimates of the conductivity ratio are in a narrow range defined by Equation 1 - i.e. if the gas bubbles occupy half the space then the resistance will be a little more than doubled (5).

$$
\left(1-\varepsilon_{g}\right)^{\frac{3}{2}}<\frac{\kappa}{\kappa_{0}}<1-\varepsilon_{g}
$$

For the simple case of parallel electrodes with plug flow of fluid that dominates the forces on the bubbles, the terminal part of the flow will have the highest gas loading. The build-up can be modelled as spatially linear so that the average level is the same as that at the halfway point. Hence the term triangular gas void ratio, $\varepsilon_{\Delta}$ shown in Equation 7, equal to half the value of the voiding at the exit point, which can be used in place of $\varepsilon_{\mathrm{g}}$ in Equation 6. Given that $V_{m}$ is molar volume in $\mathrm{m}^{3}$ per mole and $D_{I}$ is the required faradic volumetric rate of hydrogen and oxygen bubbles dose per fluid flow for an example of flotation treatment by simple electrolysis of water, a low value of $D_{I}$ of $60000 \mathrm{~A} \mathrm{~m}^{-3} \mathrm{~s}(1$ $\mathrm{A} /(1 / \mathrm{min}))$ results in a $\varepsilon_{\Delta}$ of about $1 \%$. Note that this does not depend on the gap size, though for very narrow gaps coalescence may cause the sheeting problem. Furthermore 
the utility in reducing the gap size is limited by increases in fluid pressure drops and greater difficulty in preventing contact of the electrode pairs. For example, the pressure drop in laminar flow between parallel plates is proportional to the cube of the reciprocal of the gap (5).

\section{EXPERIMENTAL TECHNIQUES}

The design of the field-trialled system is protected by NZ Provisional Patent 537700. This utilises a novel form of 6060 alloy aluminium as a corroding anode that produces a highly effective flocculant, in close proximity to a steel cathode, but separated by a simple porous nylon mesh membrane. The active surface of the corroding anode is continually replenished. Flocculant clearance into the water is achieved by high flow velocity in a flume. Hydrogen is produced outside this flow and is therefore not mixed with anodic products. The effective cathode area was about $0.4 \mathrm{~m}^{2}$, driven to current densities of up to about $100 \mathrm{~A} \mathrm{~m}^{-2}$. A smaller version was made for laboratory work.

Power supplies: 1a. D3800 DC voltage source power supply from Dick Smith Pty. with $<1 \%$ voltage ripple. 1b. Constant Current Supply Trio PD35-20. 2. Continuously adjustable full-wave rectifier composed of an earth-leakage protected $230 \mathrm{~V}$ single phase supply, a 4 A variac kindly supplied by the Physics Department of Waikato University, a step-down transformer, and four 50 A bridge-rectifier modules in parallel on a heatsink. The output was fed to the electrolyser through 80 A cable, and protected from shortcircuit by a $100 \mathrm{~A}$ high rupture current (HRC) fuse. This power supply could operate continuously at $0 \mathrm{~V}$ to $30 \mathrm{~V}$ full wave rectified rms at $0 \mathrm{~A}$ to $40 \mathrm{~A} \mathrm{rms}$, and supply up to $60 \mathrm{~A}$ for a few minutes at up to $10 \mathrm{~V}$, limited by rectifier heatsinking. The peak voltage of this supply is approximately 1.5 times the rms value, and the $100 \mathrm{~Hz}$ harmonic component is significant. The continuous variability enabled fine control of the current delivery during experimental work. Electrical measurements were made in the field with a Fluke 337 clamp-meter. $\mathrm{pH}$ measurements were made in reference to regular 2 or 3 point calibration.

Field trials of between three and six hours duration were carried out at different times of the day and week to establish the robustness of the technique despite rapid changes in the properties of the water flowing into the processor. Lab trials of between one and eight hours duration were carried out to establish performance with controlled stable inflow water states. 


\section{RESULTS}

The most surprising result in the field trials was the effectiveness of the treatment at high $\mathrm{pH}$, including very low residual aluminium and chromium levels for the $\mathrm{pH}$ of the outflow (6). The processing can lower the $\mathrm{pH}$ when the initial $\mathrm{pH}$ is above 8 . This would be expected where the anolyte and catholyte are separated, but a $\mathrm{pH}$ drop was observed even in the whole outflow. This suggests that the normal protective layer is continuously disrupted by electrolysis, and oxygen sourced from outside the electrolytic system is able to corrode additional aluminium. These effects are supported by subsequent laboratory studies and other past studies $(7,8)$.

The current-voltage characteristic was largely dependent on the conductivity and state of the anode surface (9). To a great extent the characteristic of initial current with voltage was linear, suggesting that the electrolyte and membrane dominate the total resistance. Most interestingly, in situations where the treatment was effective, the initial current with a new anode was low, but the current increased steadily over an hour or two to a level that could exceed double the initial value. In cases of low salinity the current would usually decline monotonically from the initial value and treatment was unlikely to be effective for very long, if at all. Cell voltages from $3.5 \mathrm{~V}$ to $10 \mathrm{~V}$ were effective in treating tannery effluent. Current doses (current per volumetric flow rate, or charge per volume) of between 1 and $5 \mathrm{~A} /($ litre/min) were necessary to cause good flocculation. The low end was sufficient for saline solutions, while the high end was necessary for heavily loaded tannery effluent. $1 \mathrm{~A} /\left(\right.$ litre/min) corresponds faradically to about $5.59 \mathrm{ppm}$ of $\mathrm{Al}^{3+}$ or $10.56 \mathrm{ppm} \mathrm{Al}_{2} \mathrm{O}_{3}$ equivalent.

Figures 3, 4 and 5 show the results from a trial on May 12 2005. Turbidity, measured in nephleometric turbidity units (NTU), is a good (though not linear) indicator of the amount of suspended solids in the water. Because the quality of the tannery effluent changes so quickly, the samples were taken over just a half hour period, with inflows collected at either end of the time period. The figures show that generally, the higher the dose of aluminium, the greater the reductions in outflow turbidity, $\mathrm{pH}$ and chromium, though the change of the inflow also has an impact. The cost-effectiveness of the electrolytic processing, including cost of electricity and aluminium is favourable compared to dosing with polyaluminium chloride (a commercial, partly hydrolysed flocculant).

The specialised anode has a clear advantage over other corroding anodes. Tracking of the water flow due to the normally inevitable uneven corrosion is eliminated. The clearance of flocculant from the specialised anode is high, as long as the flow speed is at least about $0.1 \mathrm{~m} \mathrm{~s}^{-1}$. This is in stark contrast to earlier models where the floc would rapidly clog the anode and block both the flow and the current.

Hydrogen production was estimated faradically around $6.96 \times 10^{-3} \mathrm{~m}^{3}$ of gas at STP per $\mathrm{m}^{3}$ of fluid treated per charge dose. Moderate treatment at about $3 \mathrm{~A} /($ litre/min) equal to $1.8 \times 10^{5} \mathrm{C} \mathrm{m}^{-3}$ - gives about 20 litres of hydrogen per cubic metre of water treated. The efficiency of hydrogen production and the fraction of energy that can be recovered from the electrical input are identical, and may be estimated by the ratio of the standard potential for electrolysis of water $(1.23 \mathrm{~V})$ to the cell voltage. For a cell voltage of $5 \mathrm{~V}$, the efficiency is about $25 \%$. 


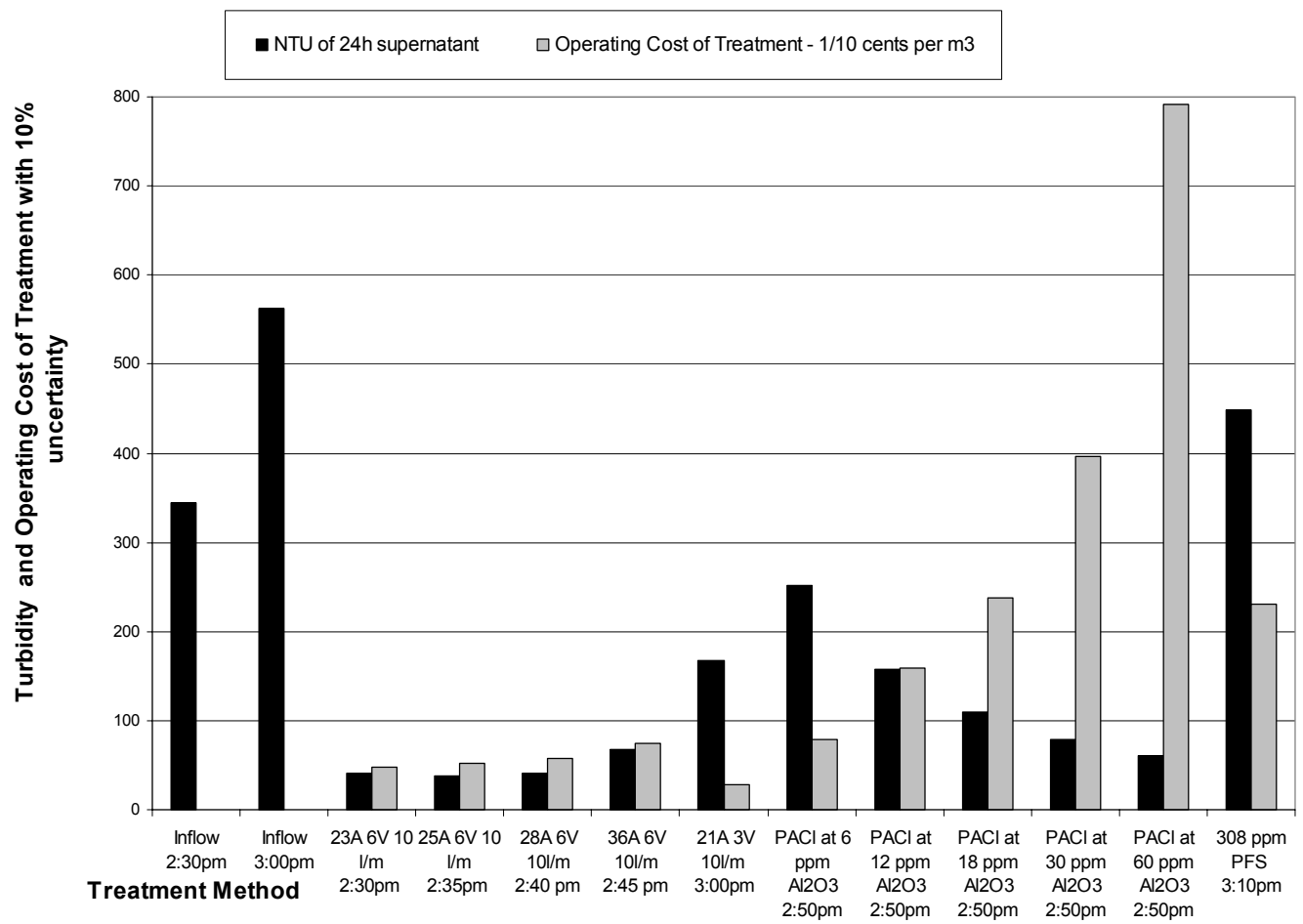

Figure 3. Comparison of Electrolytic Treatment on Tannery Effluent with polyaluminium chloride dosing. Inflow at 2:30 pm: $\mathrm{pH} 8.9,850 \mathrm{NTU}, 17250 \mathrm{uS} / \mathrm{cm}$ at $19{ }^{\circ} \mathrm{C}$; at $3 \mathrm{pm}: \mathrm{pH} 8.6,900 \mathrm{NTU}, 16560 \mathrm{uS} / \mathrm{cm}$ at $19{ }^{\circ} \mathrm{C}$.

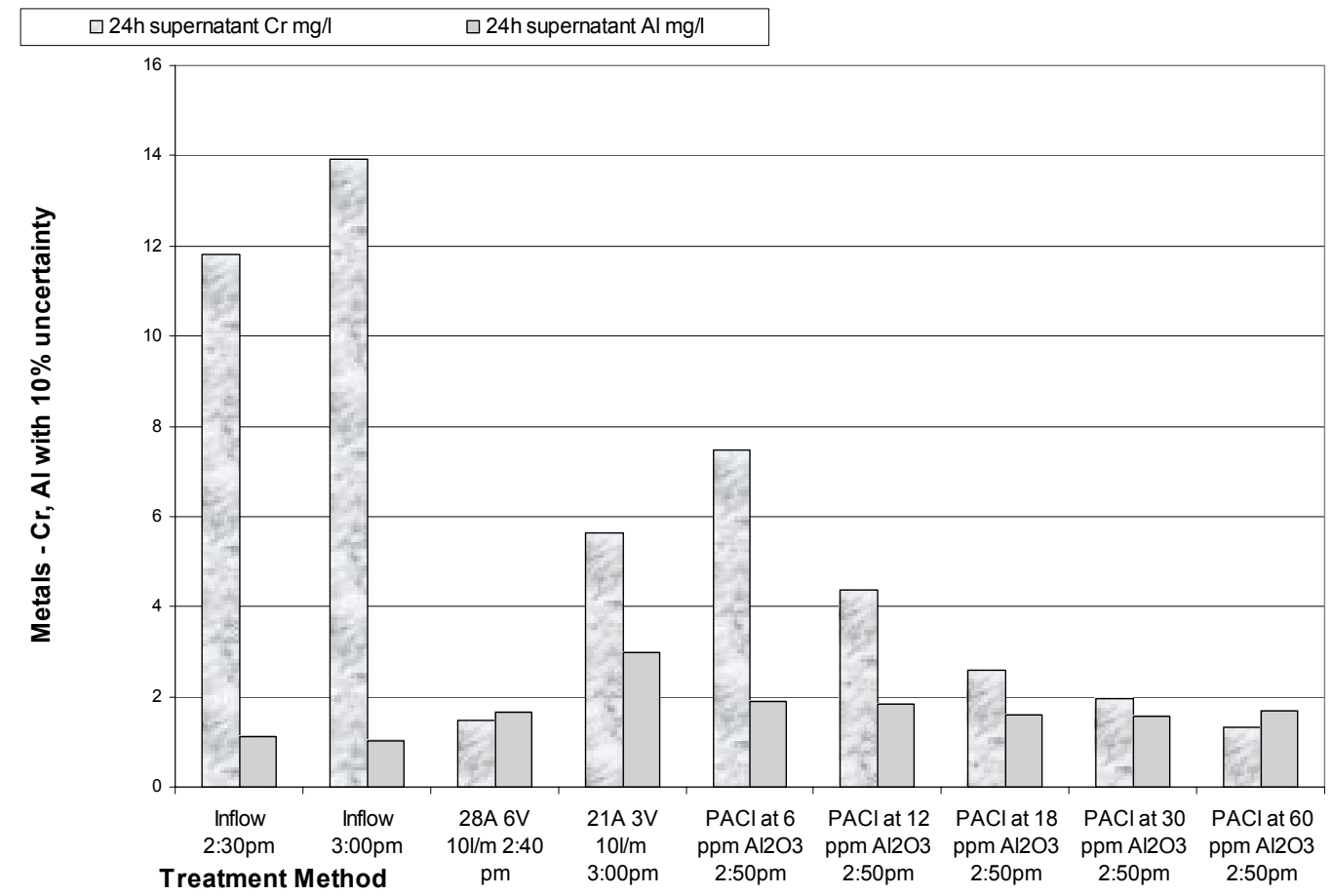

Figure 4. Corresponding residual metals data. 


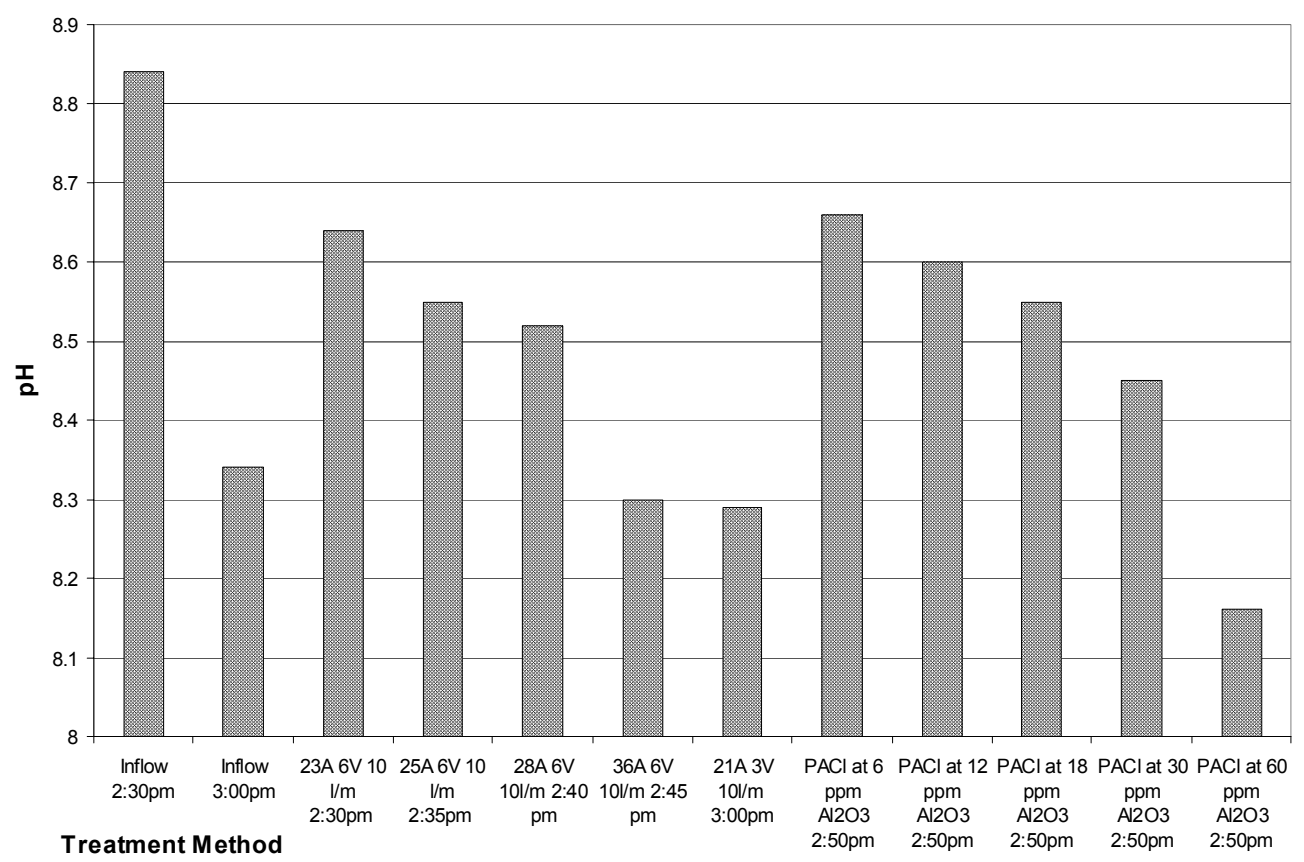

Figure 5. Corresponding $\mathrm{pH}$ data.

Curiously, while all the X-ray diffraction tests of freshly made aluminum floc have shown no clear crystal structure - that is the floc is amorphous - a sample of fresh floc composed of both aluminum and chromium in roughly similar molar proportions was found to be crystalline but with a spectrum (shown in Figure 6) not matched by any in the Philips X'Pert database. After a period of months, the amorphous pure aluminum flocc becomes crystalline and tends to be more colloidal than a floc. The stable form of the combined $\mathrm{Cr}-\mathrm{Al}$ floc has yet to be determined.

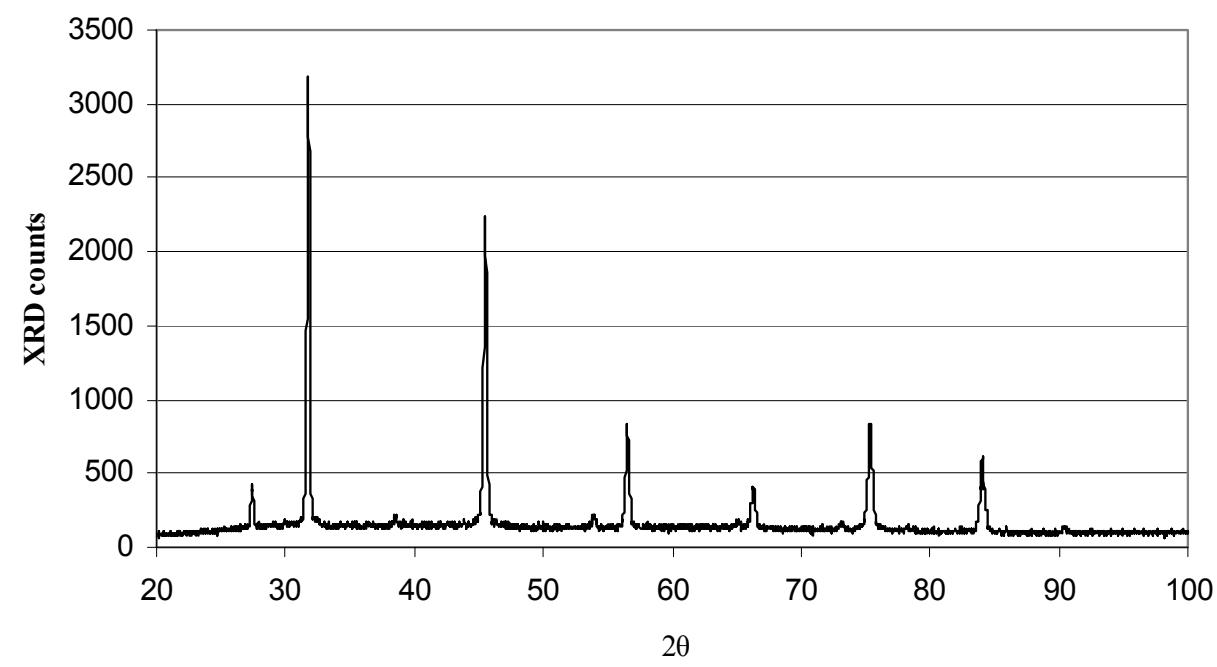

Figure 6. X-ray diffraction spectrum of $\mathrm{Cr}-\mathrm{Al}$ mineral - freeze dried from freshly made floc. 


\section{DISCUSSION}

Electrolytic processing of tannery effluent is inherently robust and partially selfregulating in the face of routine rapid variation of inflow $\mathrm{pH}$ between 8 and 10, due to the greater instability of aluminum at higher $\mathrm{pH}$ in anodic conditions. If levels of dissolved chromium and suspended solids correlate with the salinity and alkalinity, the current drawn from a simple voltage source power supply will also change appropriately.

Greater control can be achieved by using a current source regulated to deliver an appropriate charge dose, according to the level of contaminants, independent of the salinity-based conductivity. "Faradic" corrosion is largely based on the total current - but drops slightly from linearity with current density due to a drop in effective aluminum current fraction at higher cell voltage. The balance of the anodic current goes to release of oxygen in small bubbles which can be utilised to float out flocculated material. Extrafaradic corrosion arises due to reaction of externally sourced oxygen. While the anodic acidification due to faradic corrosion is balanced by cathodic de-acidification, extrafaradic corrosion results in an unbalanced decrease in the $\mathrm{pH}$.

There are inevitably difficult periods when the $\mathrm{pH}$ of the water to be treated is very high, leaving a high level of residual aluminum in the water. There are several means to combat this. If the salinity is low when the $\mathrm{pH}$ is high, which occasionally happens, a current source directed to give a high current dose will have to increase the cell voltage. This will increase the extra-faradic corrosion and hence the $\mathrm{pH}$ will be lowered more, albeit with additional power consumption.

However, to cope with realistic situations where the number of salinity and $\mathrm{pH}$ combinations is unrestricted, independent control of the faradic and extra-faradic corrosion is helpful. This can be achieved by two means:- decreasing the surface area of the reactor and increasing the current density, or by operating the power supply at less than $100 \%$ duty cycle but with higher peak current - the latter has the advantage of not requiring moving parts.

For example, if the voltage or current source is operated at $50 \%$ duty, because the linear electrolyte resistance dominates, both the peak current and voltage are increased by factor square-root two - the same average power is achieved by applying double power for half of the time. The pulsing does not have to be fast - $10 \mathrm{~Hz}$ is more than sufficient so the electrical switching losses are low. The faradic aluminium will decrease by about factor square-root two, that is to about $71 \%$ of the dc level. The extra-faradic corrosion will certainly be faster during the on-period than for dc. If that rate more than doubles for a square-root two factor increase in voltage then the $\mathrm{pH}$ drop will be greater than for $\mathrm{dc}$. At higher $\mathrm{pH}$ the extra-faradic current will increase more due to the lower stability of the aluminium - both thermodynamic and kinetic. The combination of frequency and duty cycle that maximises the extra-faradic corrosion has not been established. In many cases the total Al corroded will not change much.

The most relevant test is to compare DC with the $5 \mathrm{~ms}$ to $10 \mathrm{~ms}$ sinusoidal pulses from a full-wave rectifier because the latter is the cheapest option for an industrial power supply. From the field trials carried out so far, full-wave rectification is sufficiently effective to obviate expensive smoothing capacitors. Variable smoothing of the 
waveform might be sufficient for at least partial control of the $\mathrm{pH}$ drop - done simply by graded connection of a bank of capacitors in parallel to the supply. Lower duty cycles can be most cheaply achieved by using thyristor phase-control of the input to the step-down transformer that feeds the rectifier.

A further means of $\mathrm{pH}$ manipulation is to separate the flows into anolyte and catholyte. By putting the main flow through the anode compartment and collecting a very low rate caustic $(\mathrm{pH}>12)$ catholyte flow separately, the anolyte $\mathrm{pH}$ can be lowered considerably beyond the effect of the extra-faradic corrosion. Recycling the caustic flow to the tannery is a direct benefit.

Adding concentrated saline to the usual seepage that forms the catholyte flow is another means of manipulating the anolyte $\mathrm{pH}$ and has the additional benefit of increasing the effective conductivity of the electrolytic system without increasing the conductivity of the anolyte much. An active catholyte flow of $1 \%$ of the anolyte flow, even if it has higher $\mathrm{pH}$ than the anolyte at the inflow to the process, causes additional $\mathrm{pH}$ drop and is able to lower the voltage for a moderate charge dose significantly. As a last resort, supplying a strongly acidic catholyte flow at the inflow to the process, of about $1 \%$ of the anolyte flow, can greatly reduce the anolyte $\mathrm{pH}$ if necessary. The small active catholyte flow may be diluted slightly and will certainly become more alkaline by the time it exits the process.

If the water to be treated is at an extremely low (below 8) $\mathrm{pH}$ or alkalinity, the flocculation may be poor and all of the above $\mathrm{pH}$ decreasing effects should be minimised, otherwise the outflow will be acidic and contain colloidal aluminum.

High frequency pulsing is probably of marginal utility, as the low duty cycles required to enable full recovery of the diffusion gradients offset the gain during the on-time. However this approach is worthy of further investigation.

Very low frequency pulsing, say $100 \mathrm{~s}$ on and $10 \mathrm{~s}$ off, has a place in preventing blockage by allowing an off-time that will allow a slug of high $\mathrm{pH}$ water to remove corrosion products adhered to the anode surface. While the power is off the active acidification is off and the bound corrosion products are freed. The key is to time the off period to be greater than the transit period of the water, but not so great that the cleaning is completed to the extent that some water leaves without being flocculated. The floccing is liable to be less effective for the water that passes through during the off period and insoluble corrosion products may also be carried out during this time but they will be mixed with flocced water shortly thereafter anyway.

Filtration of the water prior to the electrolytic processing is essential in order to prevent clogging of the electrolyser's narrow gap by the coarser suspended solids. It also assists in reducing the required charge dose. Because the chrome is mostly dissolved in the raw effluent, the coarse filter effectively catches mainly organic material. The coarse filter's output supplies the electrolytic processor, with post-processing filtration. A possible sheme is shown in Figure 7. Works Filter System's proprietary porous ceramic dual media (PCDM) filters are particularly appropriate as the filter components. 


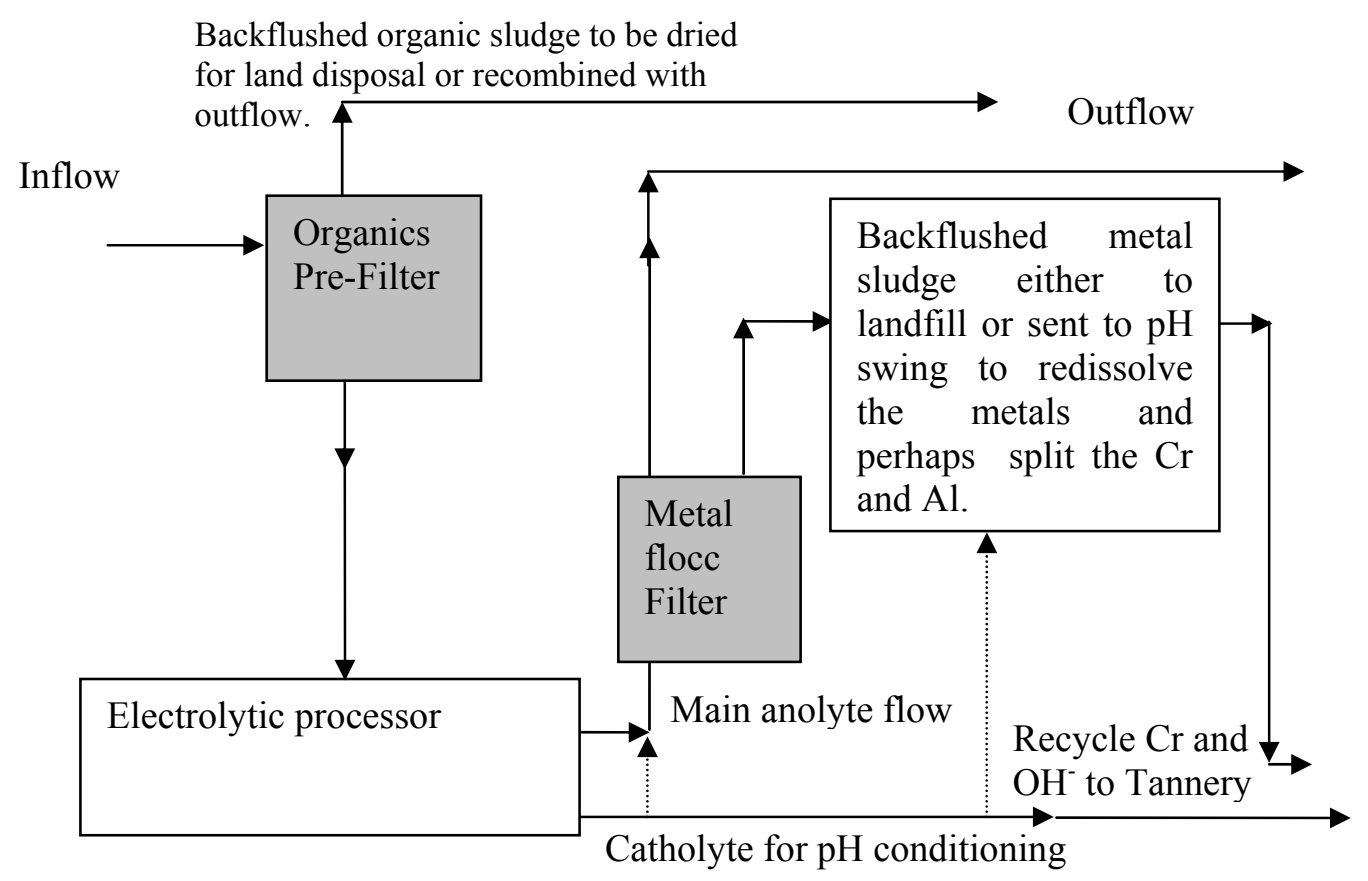

Figure 7. A complete treatment system, with flow recirculation and redirection options shown.

\section{CONCLUSIONS}

Tannery effluent can be treated effectively by electrolysis. Several treatment techniques such as flocculation and flotation can be combined in a single apparatus. The ease of direct electrical control to regulate the purification is a distinct advantage. The process is economic compared with traditional techniques and the hydrogen produced at the cathode separate to the anolyte and anodic products at an electrochemical efficiency of about $25 \%$ can be considered as a bonus.

\section{ACKNOWLEDGMENTS}

The $\mathrm{PhD}$ project work, on which this paper is based, is supported by Technology New Zealand TIF Fellowship WFSX0201 and Works Filter Systems Limited.

\section{REFERENCES}

1. L. Fassina, Journal of the American Leather Chemists Association, 33, 380 (1938)

2. P. Rohland, Kolloid-Zeitschrift, 16, 58 (1915)

3. A. Tetrault, Paper presented at Environz03, NZWWA, 2003, 2003A.

4. D. Pletcher and F. C. Walsh, Industrial Electrochemistry, 2nd ed., University Press, Cambridge (1990).

5. H. Wendt and G. Kreysa, Electrochemical Engineering: Science and Technology in Chemical and Other Industries (1999).

6. F. W. Pontius, Water Quality and Treatment - A handbook of community water supplies, 4th Ed. ed., McGraw-Hill, (1990).

7. G. Lu, J. Qu and H. Tang, Water Research, 33, 807 (1999)

8. K. Zeppenfeld, Aluminium (Isernhagen, Germany), 79, 754 (2003)

9. X. Chen, G. Chen and P. L. Yue, Chemical Engineering Science, 57, 2449 (2002) 